\title{
UMA VIDA E UMA OBRA POR COMPLETO
}

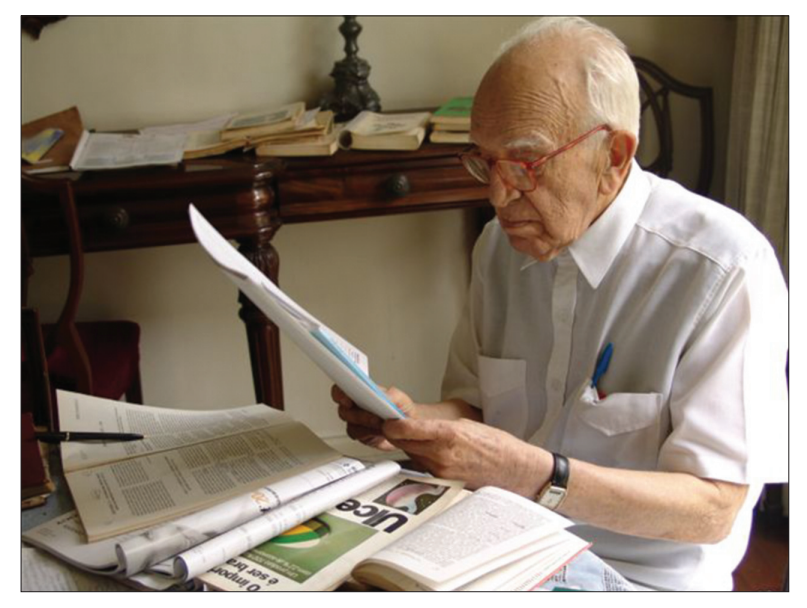

Em 26 de dezembro de 2005 faleceu, em São Paulo, o Prof. José Fernandes Pontes, pouco antes de completar 91 anos de idade, e com isto, a Gastroenterologia brasileira e latina perde um de seus maiores vultos.

Pessoa ímpar, de caráter empreendedor, inovador e humanístico, destacou-se por uma visão larga que o projetava muito além das pessoas comuns. Tenaz, deixou um legado incomparável além de ter sido responsável pela formação de gerações de profissionais que hoje ocupam as mais destacadas funções em atividades acadêmicas e diretivas em universidades nacionais e latinoamericanas.

Seu espírito inovador resultou na fundação do Instituto de Gastroenterologia de São Paulo (IGESP), inicialmente funcionando na Rua Japurá, área central de São Paulo, posteriormente, em 1964, definitiva e ampliadamente transferido para a Rua Silvia, na Bela Vista.

Esta nova concepção do IGESP constituiu um modelo avançado de estruturação de um centro de diagnóstico em Gastroenterologia, baseado em conjunto de consultórios médicos multi e interdisciplinares, concentrando em um só espaço a facilidade de realização de vários procedimentos laboratoriais através de equipamentos de alta tecnologia e, posteriormente, extensivos a várias outras especialidades médicas.

Este modelo de atendimento integrado, pioneiro naquela época, vem a ser copiado por outras grandes unidades hospitalares da cidade.

Simultaneamente, pela necessidade de se preservar o caráter científico e acadêmico da especialidade, transformou e ampliou o então "Centro de Estudos" existente no prédio inicial, no Instituto Brasileiro de Estudos e Pesquisas de Gastroenterologia-IBEPEGE, inicialmente funcionante no andar térreo do IGESP, transferido, a seguir, para sua sede definitiva na Rua Dr. Seng, a alguns passos dele.

O IBEPEGE iniciou suas atividades com o Curso de Formação de Especialistas em Gastroenterologia, com formação prática e técnica para grande número de médicos, oriundos de inúmeros Estados brasileiros e outros países latinos. Este Curso evoluiu para o nível de Mestrado, autorizado pelo Conselho Federal de Educação do MEC, constituindo-se em um dos primeiros cursos de Mestrado na área da Gastroenterologia, sendo o único ministrado por instituição privada. Ao longo do mesmo foram apresentadas 74 teses, cujos autores, dando seqüência a sua formação acadêmica, ocupam posição de destaque na direção de universidades brasileiras.

Prof. Pontes inovou, também, na criação dos cursos anuais de Atualização em Gastroenterologia, reunindo, no mês de janeiro de cada ano, os maiores nomes da especialidade nacional e sempre com a presença de eminentes professores estrangeiros convidados. Outra inovação do Prof. Pontes foi a instituição dos Cursos de Ensino Continuado, fórmula de sucesso também copiada por diversas sociedades médicas.

Graças a seus esforços, o IBEPEGE foi contemplado com o projeto FINEP, com a alocação de recursos federais, permitindo a aquisição dos mais modernos equipamentos médicos possíveis na época, possibilitando a disponibilização desses recursos para prestação de serviços à comunidade, através dos ambulatórios do IBEPEGE, além de permitir o desenvolvimento de pesquisas e elaboração de teses e trabalhos científicos, publicados em periódicos do Brasil e do exterior. 
Em 1964, o Prof. Pontes fundou a revista ARQUIVOS de GASTROENTEROLOGIA, que continua sendo um dos únicos periódicos na área da Gastroenterologia, em toda a América Latina, que possui as mais expressivas indexações, mantendo-se de forma ininterrupta por 42 anos e sempre com o mais elevado padrão científico e editorial, reconhecido nacional e internacionalmente.

A atuação médica do Prof. Pontes através de um enfoque biopsicossocial de humanização no atendimento a seus pacientes, propiciou a compreensão da abordagem Psicossomática aplicada à área médica, instalando no IBEPEGE um curso específico, aberto a profissionais da área da saúde (médicos, enfermeiros, assistentes sociais, odontólogos, psicólogos, esteticistas, etc.). Em 1964 é fundada a Associação Brasileira de Medicina Psicossomática, tendo o Prof. Pontes como um de seus incentivadores e da qual veio a ser um de seus primeiros presidentes. Foi, portanto, dos mais destacados profissionais na luta pela consolidação da idéia da necessidade de se avaliar e tratar dos aspectos emocionais e orgânicos do indivíduo como uma unidade integrada.

O Prof. Pontes teve, também, grande atuação no desenvolvimento dos estudos de eletrofisiologia do sistema digestório, com a instalação de equipamentos pioneiros no IBEPEGE e a elaboração de inúmeros trabalhos na área de motilidade e posteriores teses de mestrado. Incentivou a fundação da Sociedade Brasileira de Motilidade Digestiva, assim como a de outras especialidades como a de Endoscopia Digestiva e Hepatologia.
Em sua vida acadêmica obteve a titulação de Livre-Docência pela Universidade de São Paulo e laureado pela Academia Nacional de Medicina do Brasil e do Chile, além de receber honrarias de todas as sociedades de Gastroenterologia da América Latina e do norte do Brasil, em reconhecimento pela imensa colaboração na efetivação da Gastroenterologia como especialidade médica e na formação de profissionais dentro de uma visão humanística da Medicina, além da sua profícua produção científica.

Seu ciclo de vida foi completo, construindo em torno de seu nome não apenas uma instituição, um prédio. Deixou um exemplo de vida dedicada à Medicina e ao ensino.

Teremos saudades do nosso mestre. Torcemos para que a natureza em breve se encarregue de nos dar mais homens como este em todos os setores da vida, tornando este mundo melhor.

Fernando PARDINI ${ }^{1}$

Mounib TACLA ${ }^{2}$ Ricardo Guilherme VIEBIG ${ }^{1}$

${ }^{1}$ Editor Consultivo dos Arquivos de Gastroenterologia; ${ }^{2}$ Editor Científico dos Arquivos de Gastroenterologia. 